\title{
MKL/Myocardin-Like Protein 1
}

National Cancer Institute

\section{Source}

National Cancer Institute. MKL/Myocardin-Like Protein 1. NCI Thesaurus. Code C97298.

MKL/myocardin-like protein 1 (931 aa, $99 \mathrm{kDa}$ ) is encoded by the human MRTFA gene.

This protein is involved in both transcriptional activation and smooth muscle development. 